\title{
Teacher-Child Interactions in Chile and Their Associations With Prekindergarten Outcomes
}

\author{
Diana Leyva \\ Davidson College \\ M. Barata \\ Instituto Universitário de Lisboa (ISCTE-IUL), Cis-IUL \\ Catherine Snow \\ Harvard University
}

\author{
Christina Weiland \\ University of Michigan \\ Hirokazu Yoshikawa \\ New York University \\ Ernesto Treviño \\ Universidad Diego Portales
}

\author{
Andrea Rolla \\ Harvard University
}

\begin{abstract}
Quality of teacher-child interactions is central to prekindergarten children's learning. In the United States, the quality of teacher-child interactions is commonly assessed using the teaching through interactions conceptual framework and an associ/ated observational tool, the Classroom Assessment Scoring System (CLASS). This study examined: (a) whether there was evidence supporting three distinctive domains of teacher-child interactions in Chile (construct validity) and (b) whether these domains predicted end-of-prekindergarten language, academic, and executive function skills in Chile (predictive validity). The sample consisted of 91 Chilean prekindergarten classrooms (1,868 four-year-old children). The findings support both construct and predictive validity of the teaching through interactions conceptual framework as assessed by the CLASS in Chile. Implications for cross-country comparison of quality of teacher-child interactions in prekindergarten classrooms are discussed.
\end{abstract}

Children develop and learn, to a large extent, as a function of their interactions with adults and peers. From an ecological and developmental perspective, the quality of the interactions between adults and children is an important proximal context of children's learning and development (Bronfenbrenner \& Morris, 1998). Several studies have found that the way that adults and children interact in the classroom is critical to children's language, literacy, mathematics, cognitive, socioemotional, and self-

This study was funded by Fundación Educacional Oportunidad and Harvard Graduate School of Education. We would like to thank participating families, teachers, principals, and district staff in Chile. We also thank all the members of the Un Buen Comienzo UBC Project team in Chile and to the Harvard Center on the Developing Child. We are thankful to Katherine Masyn for her statistical support. Ernesto Treviño acknowledges funding from Fondecyt Project \# 11100493. M. Clara Barata acknowledges funding from the European Union under the Marie Curie International Incoming Fellowship (FP7-PEOPLE-2011-IIF 303242).

Correspondence concerning this article should be addressed to Diana Leyva, Psychology Department, Davidson College, Box 7136, Davidson, NC 28035. Electronic mail may be sent to dileyva @davidson.edu. regulation development (National Institute of Child Health and Human Development [NICHD] Early Child Care Research Network [ECCRN], 2005; Pianta et al., 2005). The quality of the interactions between teachers and children is considered one of the primary mechanisms through which educational experience fosters the development of children's competences (Downer, Sabol, \& Hamre, 2010).

Recent research on the relation between the quality of teacher-child interactions and children's learning and development is characterized by several features. First, these studies are largely grounded in the teaching through the interactions conceptual framework (Hamre \& Pianta, 2007). Second, many studies have used an observational measure corresponding to this framework, the

(C) 2015 The Authors

Child Development (C) 2015 Society for Research in Child Development, Inc. All rights reserved. 0009-3920/2015/8603-0009

DOI: $10.1111 /$ cdev. 12342 
Classroom Assessment Scoring System (CLASS; Pianta, La Paro, \& Hamre, 2008). Third, these studies have been conducted predominantly in the United States (Burchinal, Vandergrift, Pianta, \& Mashburn, 2010; Burchinal et al., 2008; Howes et al., 2008; Mashburn et al., 2008; Weiland, Ulvestad, Sachs, \& Yoshikawa, 2013). In this study, we contribute to this research by investigating whether and how the quality of teacher-child interactions, as conceptualized by the teaching through interactions framework and assessed by the CLASS, was valid in Chilean early childhood classrooms, and whether it predicted child outcomes. We focused on Chile because the organization of early childhood education settings in this country is in many important ways different from the U.S. context. Thus, Chile provided an excellent opportunity to examine how the organization of early childhood education settings (and the cultural values reflected in such organization) might shape the relations between adult-child interactions in the classroom and child development. Next, we discuss the teaching through interactions framework and its corresponding observational tool (the CLASS), and then discuss some organizational features of the Chilean early childhood education settings. The present study represents the second validity study of the CLASS outside the United States and the first such study in a developing country.

\section{Teaching Through Interactions Framework and Measurement}

The teaching through interactions conceptual framework is based on several developmental and educational theories including responsivity, attachment, scaffolding, self-determination, and effective teaching (e.g., Bornstein, Tamis-LeMonda, Hahn, \& Haynes, 2008; Bronfenbrenner \& Morris, 1998). According to this framework, daily interactions between children and teachers within classrooms are the primary engine for children's learning (Hamre \& Pianta, 2007). There are three domains of teacher-child interactions that are central to children's learning and development: emotional support, classroom organization, and instructional support.

Teachers' emotional support in interactions with children fosters social development and learning. When teachers are sensitive and responsive in their interactions with children, children develop a sense of security that allows them to be more engaged and motivated in classroom activities, and consequently to be more likely to benefit from instruction
(Landry, Anthony, Swank, \& Monseque-Bailey, 2009). Emotional support in the classroom includes four dimensions: positive climate (teachers' levels of warmth and respect between teachers and children and among children themselves), lack of negative climate (expressed negativity such as hostility and aggression between teachers and children and among children themselves), teacher sensitivity (teacher's responsiveness to children's academic and emotional needs), and regard for student perspectives (how teachers support children's perspectives, interests, and motivations; Pianta et al., 2008).

Classroom organization and management support children's self-regulation development, including executive function skills - the set of cognitive processes integral to the development of social and cognitive competence in young children (Raver, 2004). Teachers who model regulatory behaviors and attention help children internalize these selfregulation models, thus improving children's own self-behavior management. Classroom organization has been proposed to reflect three dimensions: behavior management (how teachers set up clear behavioral expectations and monitor, prevent, and redirect misbehavior), productivity (how well teachers manage instructional time and routines), and instructional learning formats (how teachers capitalize on students' engagement and interests; Pianta et al., 2008).

Teachers' instructional interactions with children promote learning when they are intentional, focused, direct, and use feedback loops involving students' performance. Teachers who provide children with opportunities to practice existing abilities and who scaffold complex skills enhance children's cognitive and language development (Pianta, La Paro, Payne, Cox, \& Bradley, 2002). Instructional support entails three dimensions: concept development (the degree to which teachers promote higher order thinking and focus on understanding), quality of feedback (how teachers provide feedback that encourages students' participation), and language modeling (how teachers facilitate and model language use in the classroom; Pianta et al., 2008).

Evidence to support these three distinctive domains of teacher-child interactions and their associations with child learning and development has come from use of the CLASS observational tool (Pianta et al., 2008). The CLASS was first developed for the large-scale NICHD Study of Early Child Care (see NICHD ECCRN, 1996), and later improved and extended to cover other age groups (Hamre et al., 2013). The prekindergarten version of the CLASS has been adopted as a national monitor- 
ing and professional development tool for the federal Head Start program, which serves approximately 900,000 preschool-aged children from low-income families in the United States (U.S. Department of Health and Human Services, Administration for Children and Families, 2012). In addition, several states in the United States have integrated the CLASS into their quality rating and improvement systems.

In Latin America, the CLASS is currently being used in studies on prekindergarten and kindergarten quality in Colombia, Mexico, Ecuador, Costa Rica, and Chile. Researchers in Ecuador are using the CLASS to determine whether children's learning would benefit from higher quality teacher-child interactions in the classroom (Araujo, Carneiro, Cruz-Aguayo, \& Schady, 2014). None of these studies in Latin America have been published to date. Other international studies using the CLASS are being conducted in Finland, Norway, England, Spain, Germany, and Australia. However, there is scarce international evidence on the validity of this conceptual framework in countries other than the United States. Determining whether and how the teaching through interactions framework holds across populations with different sociocultural conditions is crucial to inform and complement theoretical models used by researchers.

\section{Validity of the Teaching Through Interactions Framework and CLASS Observational Tool}

The validity of the teaching through interactions conceptual framework and its corresponding observational tool, the CLASS, has been assessed in two ways: psychometric studies of whether the three domains of teacher-child interactions are distinct (construct validity) and predictive validity to child outcomes.

\section{Construct Validity}

Two studies have examined support for the hypothesized three distinctive domains of teacherchild interactions as assessed by the CLASS, using confirmatory factor analysis (CFA). In the first, Hamre et al. (2013) tested whether observational data on a sample of over 4,000 classrooms in the United States fit the theorized three-factor model (emotional, organizational, and instructional support) versus alternative models, such as a single underlying factor (generally effective teaching), and a two-factor model (where classroom organization and emotional support belonged to a single factor).
They found that the three-factor model as assessed by the CLASS best fit the observational data in the United States. Moreover, this three-factor model was invariant from prekindergarten to sixth grade. In the second study, Pakarinen et al. (2010) examined the existence of these three domains of teacher-child interactions as assessed by the CLASS in a sample of 49 kindergarten classrooms (semirural and urban) located in two different regions in Finland. Using CFA, the authors found that the three-factor model was a good fit to the Finnish observational data but only when negative climate, one of the dimensions of the emotional support factor, was excluded from the model. According to the authors, negative climate was not a relevant dimension differentiating classroom quality in Finland as most classrooms scored similarly, at a low level; thus, this dimension had poor discriminant validity. They also tested whether a single-factor model was a better fit to the Finnish data but found no evidence to support this alternative model. This study confirmed the validity of the three distinctive domains of teacher-child interactions for the first time outside the United States.

\section{Predictive Validity}

Data collected in various regions of the United States provide some support for the extent to which teacher-child interactions as assessed by the CLASS are predictive of preschoolers' literacy, language, mathematics, and executive function skills (Burchinal et al., 2008; Howes et al., 2008; Mashburn et al., 2008; Pianta \& Hamre, 2009; Weiland et al., 2013). Some studies have empirically demonstrated that higher emotional support by teachers is linked to gains in preschoolers' academic skills including reading and math, and their social competence (Burchinal et al., 2010; Hamre \& Pianta, 2005). However, the effect sizes of these predictive relations have been small (0.01-0.08). In other studies, the links between emotional support and children's academic and social skills are null (Howes et al., 2008; Mashburn et al., 2008).

Two studies have provided empirical evidence of positive associations between classroom organization and preschoolers' self-regulation, particularly better behavioral (Rimm-Kaufman, Curby, Grimm, Nathanson, \& Brock, 2009) as well as inhibitory cognitive (Rimm-Kaufman et al., 2009; Weiland et al., 2013) control. Research with slightly older children (first graders) found no association with self-regulation skills but a significant relation between well-organized classrooms and gains in 
children's academic skills, particularly reading (Ponitz, Rimm-Kaufman, Brock, \& Nathason, 2009). The effect sizes in the aforementioned studies were small to moderate $(0.14-0.49)$.

Several studies have empirically demonstrated that teachers' instructional support predicts gains in preschoolers' language (receptive vocabulary and oral language comprehension), early mathematics, and literacy skills (letter-word identification, rhyming, and reading), beyond children's maturation alone (Burchinal et al., 2008; Burchinal et al., 2010; Howes et al., 2008; Mashburn et al., 2008). Instructional support is also associated with one measure of executive function (inhibitory cognitive control; Weiland et al., 2013). The effect size of these associations was small, ranging from 0.002 to 0.32 . Some studies have found null associations between instructional support and children's academic skills (Burchinal, Kainz, \& Cai, 2011; Weiland et al., 2013; Zaslow, Martinez-Beck, Tout, \& Halle, 2011). Other studies have found no significant relations between instructional support and socioemotional skills (Howes et al., 2008; Mashburn et al., 2008).

Some researchers have explored nonlinear relations between domains of teacher-child interactions and child outcomes in the United States (Burchinal et al., 2010; Burchinal, Kainz, et al., 2011 Weiland et al., 2013). The rationale behind these studies is that, until the quality of teacher-child interactions (as assessed by the CLASS) reaches a minimal level, a positive association with child outcomes might not be observed. Burchinal, Kainz, et al. (2011) tested for quadratic relations between the three domains of teacher-child interactions and children's socioemotional, language, literacy, and mathematics skills and found that these quadratic relations were statistically significant in several cases. In that study, these domains of teacher-child interactions were better predictors of child outcomes when they were in the higher range. Weiland et al. (2013) also found evidence for significant quadratic relations between the three domains of teacher-child interactions and one measure of children's executive function (inhibitory control). Furthermore, using threshold analyses Burchinal et al. (2010) found that instructional support was a stronger predictor of higher language, reading, and mathematics skills in higher than lower quality classrooms. In turn, emotional support was a stronger predictor of higher social skills and lower levels of behavior problems in higher than in lower quality classrooms. The effect sizes in the aforementioned studies were small, ranging from -0.12 to 0.34 (with negative relations reflecting negatively valenced outcomes).
Only one study outside the United States has assessed the associations between teacher-child interactions and child outcomes (Pakarinen et al., 2011). In this study, higher instructional support in Finnish classrooms was associated with lower taskavoidant behavior in kindergarteners, which was in turn related to better children's math skills (Pakarinen et al., 2011). The effect size of this association was not reported, and no other child outcome was examined in this study. No associations between task-avoidant behavior and emotional support or classroom organization were found.

\section{Early Childhood Education Settings for Children Ages 4-6 in Chile}

Culture shapes the way that adults and children interact and the patterns of adult-child interactions that matter for children's development (Vygotsky, 1978). Several studies have demonstrated that depending on the sociocultural practices and the way learning settings are conceived and organized, children in certain communities may learn more from observation and listening than from action and verbalization (Rogoff, 2003). In non-child-centered societies, like much of Latin America, adults and children have marked statuses, adults seldom modify their speech for children, adults tend to engage in more unilateral decision making, and there is a great emphasis on values such as respeto (respect for others and self in different social groups/situations) and educación (teaching children to be moral, responsible, and socially skilled persons; Halgunseth, Ispa, \& Rudy, 2006).

The way that Chilean early childhood education settings are organized for children ages 4-6 reflects some of these sociocultural values and practices that are pervasive in Latin America. Next, we provide a snapshot of early education in Chile for children ages 4-6. This snapshot is not intended to be exhaustive. Rather, it focuses mainly on public sector services and aims to provide a framework for exploring differences in the quality of teacher-child interactions based on particular sociocultural conditions.

Chile is known worldwide for having advanced state-of-the art policies for early childhood education such as the social protection program, Chile Crece Contigo (Chile Grows with You), which provides comprehensive care for children from lowincome households (Peralta, 2011). Education for Chilean children ages $4-6$ is not compulsory but is subsidized by the government for low-income families. About $80 \%$ of 4 -year-olds are enrolled in a 
public early education program (Ministerio de Educación, 2013). Center-based education for children ages 4-6 in Chile is provided by public-sector entities (e.g., public elementary school prekindergarten programs) and non-public-sector entities (e.g., private independently operated not-for-profit programs such as faith-based centers, and formal for-profit center-based care).

An important characteristic of early childhood education settings for children ages 4-6 in Chile is the way instruction is organized, which in turn reflects specific cultural values, beliefs, and practices in this country. In Chile, children's skill development is mainly promoted through whole-group activities such as oral routines (singing and talking), free-drawing, and free-play (Yoshikawa et al., in press). Small group activities (e.g., activity centers) are rare in Chilean prekindergarten and kindergarten classrooms. There are several reasons for the prevalence of whole-group instruction in the early years in Chile. First, there is a high staff-child ratio. On average, there are two adults (a teacher and a teacher aide) for every 35 children in prekindergarten classrooms and two adults for every 45 children in kindergarten classrooms in public schools (Ministerio de Educación, 2013). With such high staffchild ratios, it is hard for teachers to simultaneously engage small groups of children in different activities while providing individualized support to all children. Second, classrooms tend to be small in size, which restricts the possibility of having different "corners" or "stations" with activities through which children can rotate during the school day. Classrooms are not thought of as places for children to move around. The typical setting involves small desks and chairs for every child, all facing the teacher and the blackboard. Children are expected to sit and listen for fairly long periods of time. Third, and perhaps more importantly, a Chilean norm, as is the case with some other Latin American cultures, is to place a relatively high value on relationships, the social group, and group cohesion or harmony (Harwood, Leyendecker, Carlson, Asencio, \& Miller, 2002).

Thus, young children are expected to learn in early childhood programs how to interact, respect, and get along with their peers. There is less emphasis on developing the child's instrumental independence, that is, the ability to perform tasks without an adult's help (Harwood et al., 2002). Consequently, teachers typically assist prekindergarten children in everyday routines such as eating, getting dressed (i.e., putting on jackets), and tidying up after themselves. Overall, the typical school day is not very structured and a high percentage of the day is spent in noninstructional activities such as eating snacks, recess, and transitions (Strasser, Lissi, \& Silva, 2009).

These sociocultural differences in early childhood education (e.g., beliefs about independence and group cohesion, emphasis on whole-group instruction, classroom space arrangements) present an excellent opportunity for examining the cross-cultural validity of the U.S.-designed and U.S.-based teaching through interactions framework and the CLASS measurement tool.

\section{The Present Study}

In the present study, we examined two research questions. First, we investigated whether there is evidence supporting the existence of three distinctive domains of teacher-child interactions, as assessed by the CLASS, in urban public prekindergarten programs in Chile. Second, we examined whether these three domains of teacher-child interactions predicted children's language, early literacy, early numeracy, and executive function abilities. We selected these outcomes both because of their developmental importance and because we aimed to make comparisons with prior published studies, which focused on these abilities (Burchinal et al., 2008; Howes et al., 2008; Mashburn et al., 2008; Pianta \& Hamre, 2009; Weiland et al., 2013). In line with prior research (Burchinal et al., 2008; Burchinal et al., 2010; Burchinal, Kainz, et al., 2011; Howes et al., 2008; Mashburn et al., 2008; Weiland et al., 2013), we tested for both linear and quadratic associations between the quality of teacher-child interactions as assessed by the CLASS and child outcomes, and used threshold (spline regression) techniques to determine whether the associations were stronger in certain quality ranges.

Given the characteristics of early childhood education settings in Chile, particularly in the type and frequency of instructional practices and the way classrooms are organized, which reflect specific sociocultural values and practices, we recognized the possibility that the domains of teacher-child interactions identified by the teaching through interactions conceptual framework and assessed by the CLASS in the United States might be different in Chile. This would indicate that domains of teacher-child interactions, as assessed by the CLASS, are subject to the particularities of early childhood education settings and the cultural beliefs and practices that support them. However, it was also possible that, regardless of the particularities in 
instructional practices and organization in Chilean classrooms, these domains of teacher-child interactions identified by the teaching through interactions conceptual framework would be invariant in this particular country.

We expected to find small but significant associations between the three domains of teacher-child interactions as assessed by the CLASS and child outcomes.

\section{Method}

\section{Participants and Setting}

Our sample was composed of 91 public prekindergarten classrooms in 64 schools and included 1,868 children. Schools were drawn from six municipalities of Chile's capital and largest city, Santiago. The municipalities were sampled to represent municipalities in Santiago with a high proportion of at-risk children, defined as a minimum of $20 \%$ atrisk children although most schools had much higher percentages $(20 \%-70 \%)$. In Chile, at-risk children are identified by the Ministry of Education based on parent education, family income, and whether the family is a beneficiary of government subsidy (social and health benefits). Thus, children in the sample were predominantly from low-income families. Schools were recruited through municipal authorities, including representatives from mayors' offices and departments of education and health, and invited to participate in the study. More details on how municipalities and schools were selected in this study are available elsewhere (Yoshikawa et al., in press). All children in the Chilean sample were Spanish-speaking monolingual 4-year-olds, and $52 \%$ were female. Active parental consent was obtained for children to participate in our study and was obtained for $98.5 \%$ children in participating schools and classrooms. Previous analyses showed that our sample was representative of a broader population of children and families from lower income municipalities in the city of Santiago based on the fourth-grade Chilean national reading and math (Sistema Nacional de Evaluación de Resultados de Aprendizaje [SIMCE]) scores, and a national composite variable indicating socioeconomic risk (Yoshikawa et al., in press).

Teachers' mean age was 45.58 years, $46 \%$ had postgraduate education, and $58 \%$ had experience teaching at a private school (compared to public schools, private schools tend to be better funded and to pay teachers better in Chile). Sixteen percent had been teaching less than 5 years, $25 \%$ had
5-14 years of teaching experience, and 58\% had 15 or more years of teaching experience. Thirty-two schools and 53 classrooms (50\% of schools and $58 \%$ of classrooms) received an intervention program during the prekindergarten year. The two major foci of this intervention were language and health teaching practices. Importantly, the intervention did not involve using the CLASS as a professional development tool.

\section{Procedures}

\section{Classroom-Level Assessment}

Classrooms were videotaped for the entire duration of a randomly chosen school day (approximately $4 \mathrm{hr}$ ) at the end of prekindergarten. Care was taken with scheduling so that classroom videotaping occurred at times that were not disruptive and on days that were typical of the usual environment for that classroom (i.e., not on a day when a field trip was planned, nor when half the class, or the regular teacher, was out sick).

Criteria to select four 20-min video segments (cycles) to code classroom videotapes were developed based on the general live observation procedure guidelines included in the CLASS manual (Pianta et al., 2008). These criteria included: (a) 20 contiguous min without interruption, (b) segments included instructional time and noninstructional time (snack, transitions), (c) segments included a sampling of the school day (beginning, midday, and end of the day), and (d) at all times there were at least five children and a teacher or teacher aide in the video. In this way, the selected segment was representative of the average experience of a child in a classroom. Importantly, the CLASS has been validated for use in coding classroom videotapes (see Pianta et al., 2008). Several other studies have used the CLASS with videotapes of classrooms in the United States (Allen et al., 2013) and in Latin America (Araujo et al., 2014).

\section{Child Assessments}

Children were assessed at the beginning and end of prekindergarten. All assessors were Chilean and had a college degree in social sciences or education. Assessors went through an intensive training, which included practice administering the assessments (role play with other assessors and with children from schools not participating in the study). This team of assessors was different from the team that assessed the quality of teacher-child 
interactions using the CLASS. To guarantee reliability in assessment administration, expert assessors visited the assessors during the 1st month of data collection. These experts gave continuous feedback to assessors to ensure reliability. Child assessments were conducted during one or two individual 30to 50-min "pull-out" sessions. Assessors built rapport with the child and spent time in the classroom before assessing them individually. The order of administration of the tests was systematically varied. After each session, assessors rated the child's learning behaviors and the task approach observed during the session.

\section{Measures}

\section{Teacher-Child Interactions}

The quality of teacher-child interactions was assessed using the CLASS (Pianta et al., 2008). The CLASS consists of three domains of teacher-child interactions (emotional, organizational, and instructional support) and involves 10 dimensions: positive climate, negative climate, teachers' sensitivity, regard for student perspectives, behavior management, productivity, instructional learning formats, concept development, quality of feedback, and language modeling. This observational tool is based on a 7-point scale as follows; scores of 1 and 2 indicate low quality; scores of 3,4, and 5 indicate mid range of quality; and scores of 6 and 7 indicate high quality.

A team of assessors went through a rigorous CLASS reliability process that included first passing a reliability test after training using U.S. classrooms videos (as any trained CLASS assessor in the United States would do), and then a second reliability test using Chilean classroom videos. The average Cohen's kappa was .89. Trained assessors watched each of the four classroom video segments (cycles) for $20 \mathrm{~min}$ and then coded for about $10 \mathrm{~min}$, as recommended by the CLASS manual.

\section{Children's Language}

We used the Picture Vocabulary subtests of the Woodcock-Muñoz Language Survey-Revised Spanish Form (WMLS-R; Woodcock, Muñoz-Sandoval, Ruef, \& Alvarado, 2005). This subtest measures receptive and expressive vocabulary. Past research has demonstrated high levels of internal reliability, predictive validity, and concurrent validity for this subtest (Schrank et al., 2005). In all analyses, we used raw scores for the subtest.

\section{Children's Early Literacy}

We used two subtests of the WMLS-R (Woodcock et al., 2005). The Letter-Word Identification test assesses children's ability to recognize letters and words. The Dictation subtest measures prewriting (e.g., drawing lines, copying letters) and writing skills (e.g., upper- and lowercase letters, words). Both subtests have high levels of internal reliability, predictive validity, and concurrent validity (Schrank et al., 2005). Raw scores were used in all analyses.

\section{Children's Early Numeracy}

We administered the Spanish version of the Applied Problems subtest, which is part of the Woodcock-Muñoz Batería III Pruebas de Aprovechamiento, Spanish Form (Muñoz-Sandoval, Woodcock, McGrew, \& Mather, 2005). Past research has demonstrated high levels of internal reliability, predictive validity, and concurrent validity for this subtest (Schrank et al., 2005). In our analysis, we used the raw score total as an outcome.

\section{Children's Executive Function}

We used the Pencil Tapping (PT; Diamond \& Taylor, 1996) and the Dimensional Change Card Sort (DCCS; Zelazo, 2006) tasks to assess children's executive function skills. The PT task measures cognitive inhibitory control, that is, the ability to suppress prepotent responses (Bierman et al., 2008). Children exhibiting cognitive inhibitory control can stop automatic responses and behaviors and use more appropriate ones (Diamond \& Taylor, 1996). In the PT task, the child was asked to tap twice if the evaluator tapped once and tap once if evaluator tapped twice. Assessors first administered a set of practice trials to ensure that children understood the rules of the task. Children who passed the practice were then given 16 total trials. Scores represented the correct number of trials out of 16 . The DCCS task measures children's attention shifting or cognitive flexibility. In the DCCS, children were shown target cards that varied along the dimensions of color and shape (e.g., red and blue, rabbits and boats). Children were asked to sort the cards according to one dimension (shape or color) and then they were asked to sort the cards according to the other dimension. To confirm that children understood the rules, assessors administered practice items, followed by six trial items. To limit the 
load on children's working memory, between each item, either the child or the assessor repeated the sorting rule. The DCCS final total score represented the number of trials (of six) in which the child inhibited the prior criterion and correctly sorted the cards according to the new criterion. The order of the dimensions tested was counterbalanced (half of the children were asked to sort by shape first and then by color, while the other half were asked to sort first by color and then by shape). Both tasks were administered in Spanish.

\section{Child-Level Control Variables}

We controlled for child age and gender in analyses examining associations between domains of teacher-child interactions and child outcomes. Children's age was measured in months (Age). We used a dichotomous indicator for gender (MALE), with male coded 1 and female coded 0 . These covariates have been shown to predict child outcomes and have been commonly included in studies using the teaching through interactions conceptual framework (Burchinal et al., 2008, 2010; Howes et al., 2008; Mashburn et al., 2008).

\section{Teacher-Level Control Variables}

To improve precision, remove potential omitted variables bias, and in keeping with prior research (Howes et al., 2008; Mashburn et al., 2008; Pakarinen et al., 2011), in addition to controlling for child demographics, we also controlled for characteristics of teachers (e.g., teacher qualifications) that: (a) are part of the structural quality of classrooms and are known to influence child outcomes (Howes et al., 2008; Mashburn et al., 2008), and (b) are deemed important in the Chilean context (Ministerio de Educación, 2013).

Teacher covariates were teacher age in years (TEACHER_AGE), dichotomous variables reflecting private school teaching experience (PRIVATE), teacher postgraduate education (POSTGRAD), and teacher experience. Postgraduate education entails a 1-year teacher professional development course on a specific topic (e.g., special education) taken at a college or university and leading to a diploma. These postgraduate diplomas are not equivalent to a master's degree in Chile. Teaching experience was represented by a set of categorical dummy variables corresponding to less than 5 years, 5-14 years, and 15 or more years; each variable was coded as 1 if the teacher fell into this category and 0 otherwise. All teacher variables were obtained from teacher surveys. If there was more than one lead teacher in the classroom, we averaged the teacher variables to create one classroom-level score (we did this for 25 of 90 classrooms). Although having more than one adult certified and/or functioning as a lead teacher in the classroom is not a common practice in Chile, it sometimes occurs given the specific hiring or class size conditions of certain schools.

\section{Data Analytic Approach}

To address our first research question-Is there evidence supporting the existence of three distinctive domains of teacher-child interactions, as assessed by the CLASS, in Chile?-we first fitted a CFA model to the Chilean sample. We fitted a three-factor model, followed by alternative two-factor models (classroom organization and emotional support as one factor, and instructional support as the other) and single-factor models. In these analyses, we freed up the intercepts for all observed variables. We used chi-square difference testing to compare model fit between the three-factor model and alternative models.

To address our second research question-Do these domains of teacher-child interactions, as assessed by the CLASS, predict children's end-ofprekindergarten language, early literacy and numeracy, and executive function in the Chilean sample?-we used multilevel analyses techniques to adjust parameter estimates and standard errors for the clustering of children in schools (Murnane \& Willett, 2010). All models included random effects for schools and fixed effects for municipalities.

To allow comparability between this and previous studies' findings (Burchinal et al., 2008; Howes et al., 2008; Mashburn et al., 2008; Pianta \& Hamre, 2009; Weiland et al., 2013), we used regression rather than structural equation modeling techniques to examine the associations between domains of teacher-child interactions and child outcomes. We fit separate models per outcome, one for each of the domains of teacher-child interactions, controlling for child scores at the beginning of prekindergarten, child and teacher characteristics, and municipality. In line with Burchinal, Kainz, et al. (2011) and Weiland et al.'s (2013) studies, we tested for both linear and quadratic associations between the three domains of teacher-child interactions and child outcomes. To test whether associations were stronger in certain quality ranges (i.e., threshold analyses), we used spline regression techniques, in which we allowed the fitted line to change slope but not intercept at a particular knot or threshold. Thresholds were set approximately at the levels considered 
"good" by CLASS developers: 5 for emotional support and classroom organization (Pianta et al., 2008). The threshold for instructional support was set to 2 based on our sample distribution (see Burchinal et al., 2010; Burchinal, Xue, Tien, Auger, \& Mashburn, 2011; Weiland et al., 2013, for a similar procedure). CLASS scores were calculated as unitweight averages of the dimensions within each domain of teacher-child interaction.

The percentage of missing classroom data at the end of prekindergarten was $16 \%$. The percentage of missing child data ranged from $2 \%$ to $23 \%$ at the beginning of prekindergarten and from $8 \%$ to $15 \%$ at the end of prekindergarten. In all models, we assumed data were missing at random. In CFA models, we used full information maximum likelihood to impute missing data (Graham, 2009). In multilevel models, we used multiple imputations techniques (with 100 imputations) following Graham (2009).

\section{Results \\ Program Effects}

Before exploring our research questions, we first conducted CFA to determine whether there was measurement noninvariance in the Chilean sample. This was important because 53 of the Chilean classrooms received an intervention during the prekindergarten year and 38 did not (see Yoshikawa et al., in press, for details). In these analyses, we were not interested in whether the intervention changed the mean structure of the CLASS scores but whether it changed the measurement model. We compared the factor loadings and fit statistics of an unconditional model (three-factor model) with two other models including the intervention variable. Because the factor loadings and the fit statistics were very similar, we concluded that the intervention may have changed the mean structure but not the measurement model. Thus, the intervention variable was not included in further analysis.

\section{Domains of Teacher-Child Interactions in Chile}

Table 1 shows the correlation matrices for the domains of teacher-child interactions, as assessed by the CLASS, in the Chilean sample. Overall, CLASS dimensions within each domain of teacherchild interactions were modestly to moderately correlated in the Chilean sample. For example, positive climate and behavior management showed a 0.66 correlation in the Chilean sample $(p<.001)$ and regard for student perspectives and quality of feedback showed a 0.46 correlation $(p<.001)$. Table 2 shows the descriptive statistics of the CLASS domains of teacher-child interactions in Chile. The means of the emotional and instructional support but not classroom organization domains were slightly lower in the Chilean sample than what has been reported by the prior literature in the United States (approximately $M=5.50$ for emotional support, $M=2.00$ for instructional support, $M=4.20$ for classroom organization; see Burchinal et al., 2008; Burchinal et al., 2010; Howes et al., 2008; Mashburn et al., 2008; Rimm-Kaufman et al., 2009;

Table 1

Descriptive Statistics and Correlation Matrices Among Dimensions of Teacher-Child Interactions Assessed by the CLASS

\begin{tabular}{|c|c|c|c|c|c|c|c|c|c|c|}
\hline & PC & $\mathrm{NC}$ & TS & RSP & $\mathrm{BM}$ & PD & ILF & $\mathrm{CD}$ & QF & LM \\
\hline$M$ & 4.66 & 1.13 & 3.81 & 3.15 & 4.86 & 4.46 & 3.53 & 1.53 & 1.65 & 2.08 \\
\hline$S D$ & 0.71 & 0.21 & 0.91 & 0.86 & 0.78 & 0.77 & 0.74 & 0.54 & 0.60 & 0.74 \\
\hline PC & 1.00 & $-0.21 \dagger$ & $0.62^{* * *}$ & $0.45^{* * *}$ & $0.66^{* * *}$ & $0.50^{* * *}$ & $0.50^{* * *}$ & $0.39^{* * *}$ & $0.44^{* * *}$ & $0.53^{* * *}$ \\
\hline $\mathrm{NC}$ & & 1.00 & $-0.22^{*}$ & -0.03 & $-0.30 * *$ & $-0.27^{*}$ & 0.02 & 0.03 & -0.05 & -0.02 \\
\hline TS & & & 1.00 & $0.61^{* * *}$ & $0.63^{* * *}$ & $0.56^{* * *}$ & $0.60^{* * *}$ & $0.44^{* * *}$ & $0.55^{* * *}$ & $0.43^{* * *}$ \\
\hline RSP & & & & 1.00 & $0.27^{*}$ & $0.30 * *$ & $0.59^{* * *}$ & $0.33 * *$ & $0.46^{* * *}$ & $0.32 * *$ \\
\hline $\mathrm{BM}$ & & & & & 1.00 & $0.67^{* * *}$ & $0.40^{* * *}$ & $0.35^{* * *}$ & $0.32^{* * *}$ & $0.40^{* * *}$ \\
\hline PD & & & & & & 1.00 & $0.51^{* * *}$ & $0.47^{* * *}$ & $0.32^{* * *}$ & $0.40^{* * *}$ \\
\hline ILF & & & & & & & 1.00 & $0.39^{* * *}$ & $0.43^{* * *}$ & $0.41^{* * *}$ \\
\hline $\mathrm{CD}$ & & & & & & & & 1.00 & $0.68^{* * *}$ & $0.66^{* * *}$ \\
\hline QF & & & & & & & & & 1.00 & $0.66^{* * *}$ \\
\hline LM & & & & & & & & & & 1.00 \\
\hline
\end{tabular}

Note. $N=91$. To facilitate comparisons across studies, we report negative climate scores in this table. However, we used negative climate reversed scores in all analyses. Percentage missing data was $16 \%$. PC = positive climate; NC = negative climate; TS $=$ teacher sensitivity; RSP = regard for student perspectives; $\mathrm{BM}=$ behavior management; $\mathrm{PD}$ = productivity; ILF = instructional learning formats; $\mathrm{CD}=$ concept development; $\mathrm{QF}=$ quality of feedback; $\mathrm{LM}=$ language modeling.

$\dagger p<.10 . * p<.05 . * * p<.01 . * * * p<.001$. 
Table 2

Descriptive Statistics for Domains of Teacher-Child Interactions Assessed by the CLASS at the End of Prekindergarten

\begin{tabular}{lccc}
\hline & $M$ & $S D$ & Range (min-max) \\
\hline Emotional support & 4.65 & 0.54 & $3.37-5.92$ \\
Instructional support & 1.75 & 0.55 & $1.00-3.80$ \\
Classroom organization & 4.29 & 0.63 & $2.50-5.66$ \\
\hline
\end{tabular}

Note. $N=91$. Percentage missing data was $16 \%$. CLASS $=$ Classroom Assessment Scoring System.

Weiland et al., 2013). Means were higher than reported in a recent study of kindergarten in Ecuador for emotional support and instructional support (4.07 and 1.15, respectively) but lower for classroom organization (4.79; C. Van Der Werf, personal communication, February 20, 2014).

For our first research question, a CFA model showed that the three-factor model did not fit the data well in the Chilean sample, $\chi^{2}(32)=85.58$, $p<.001, \quad$ CFI $=0.87, \quad$ TLI $=0.82, \quad$ RMSEA $=0.14$, SRMSR $=0.07$, where CFI $=$ comparative fit index,
TLI $=$ Tucker-Lewis reliability index, RMSEA = root mean square error approximation (square root of the estimated discrepancy due to approximation per degree of freedom), and SRMSR = standardized root mean square residual (standardized difference between the observed covariance and predicted covariance). Modification indexes suggested that the fit of the model would increase if we allowed the residuals of the following observed variables to correlate: behavioral management and positive climate, productivity and teacher sensitivity, negative climate and productivity, and instructional learning formats and regard for student perspectives. When these residual correlations were included in the model, the three-factor model had acceptable fit, $\chi^{2}(28)=58.28, \quad p<.001, \quad$ CFI $=0.93, \quad$ TLI $=0.88$, RMSEA $=0.11$, SRMSR $=0.06$.

In chi-square difference testing, we found that in this Chilean sample, the three-factor model fit statistically significantly better than the two-factor modelwith emotional support and classroom organization as a single factor; Chile $d f(2): \chi^{2}$ difference

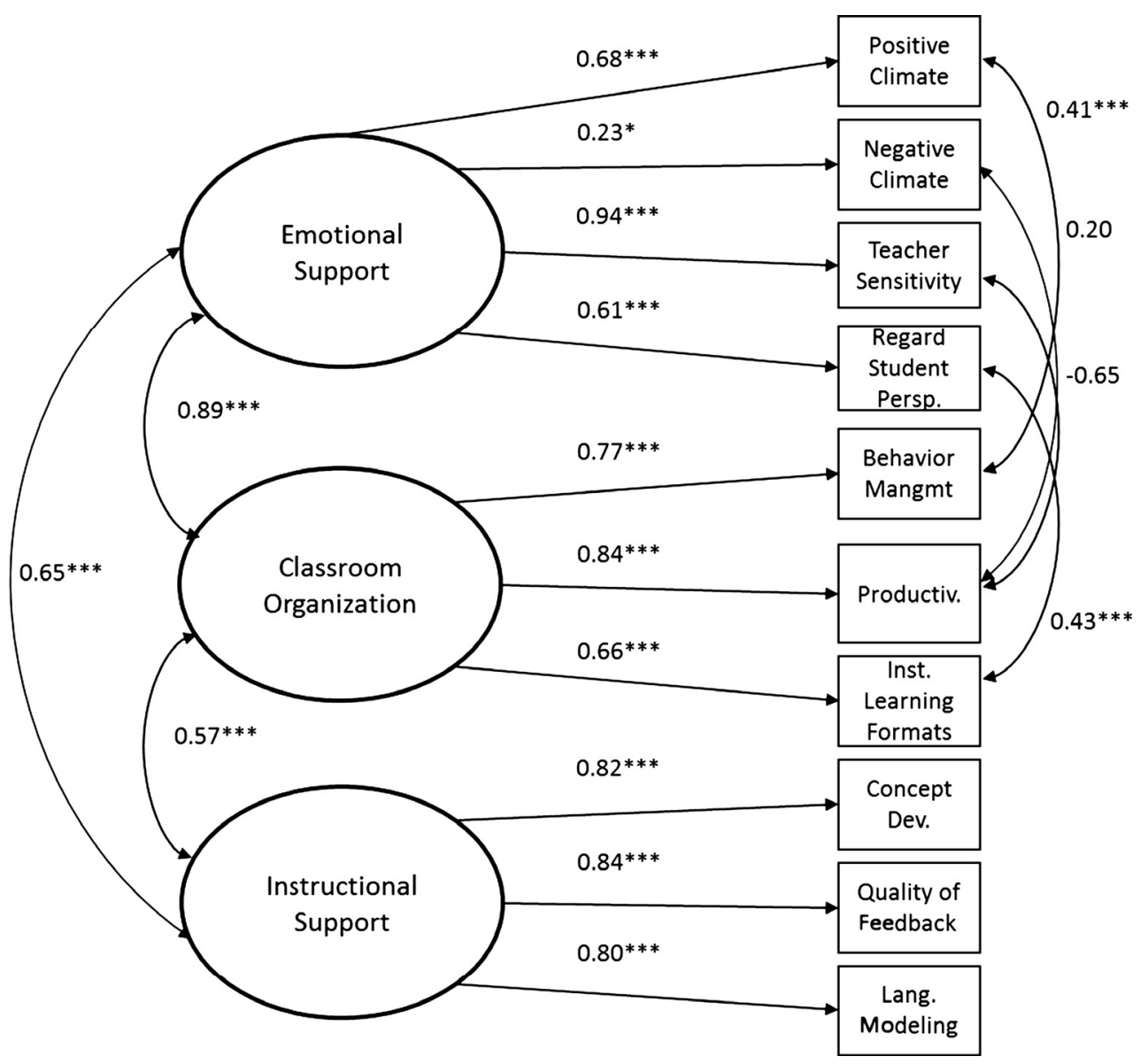

Figure 1. Fitted confirmatory factor analyses model in the Chilean sample. $* p<.05 . * * * p<.001$. 
$=7.27$, and the single-factor model - Chile $d f(3): \chi^{2}$ difference $=61.30$. Figure 1 shows the factor loadings and correlations for the three-factor model in the Chilean sample. Overall, factor loadings were lower in the Chilean sample than in the prior literature in the United States (see Hamre et al., 2013). Only five factor loadings were above .80 in the Chilean sample. Importantly, the lowest factor loading in the Chilean sample was negative climate (0.23), which was significantly lower than all other factor loadings in this sample (above 0.61). In summary, we found evidence supporting the existence of three distinctive domains of teacher-child interactions in Chile.

\section{Associations Between Domains of Teacher-Child Interactions and Child Outcomes}

In accordance with our previous findings that a three-factor structure provided the best fit to the Chilean data, we examined the associations between these domains of teacher-child interactions, as measured by the CLASS, and child outcomes in Chile. Table 3 shows the descriptive statistics (raw scores) for child outcomes (language, early literacy and numeracy, and executive function) at the beginning and at the end of prekindergarten. Descriptives for Woodcock-Muñoz standard scores are provided in Table S1 in the online Supporting Information.

As a robustness check, we conducted multilevel analyses twice, first controlling for teacher covariates, and second not controlling for these covariates. The strength, direction, and significance of the associations found after controlling for teacher covariates were very similar to that when no teacher covariates were included in the models. Results are available upon request. We reported analyses including teacher covariates because by controlling for teacher covariates, we were able to determine the variation of child outcomes that was attributed to classroom processes (teacher-child interactions) above and beyond that attributed to classroom structure (teacher characteristics). Hence, teacher covariates increased our data-analytic precision, removed potential omitted variables bias, and allowed us to compare our findings with the prior literature (Howes et al., 2008; Mashburn et al., 2008; Pakarinen et al., 2011). We controlled for clustering at the school level only because we found zero clustering at the classroom level, and no meaningful differences when we adjusted for clustering at the school level only versus at both the school and classroom levels.

Linear and Quadratic Associations Between Domains of Teacher-Child Interactions and Child Outcomes in Chile

Table 4 shows the results of the multilevel modeling analyses examining the linear and quadratic relations between the three domains of teacherchild interactions assessed by the CLASS and child outcomes, controlling for child and teacher demographic variables, and child baseline skills. We translated all detected statistically significant linear relations shown in Table 4 into an effect size by multiplying the predictor's coefficient by the standard deviation of the predictor and dividing by the standard deviation of the outcome (for a similar procedure, see Burchinal et al., 2010; Rimm-Kaufman et al., 2009; Weiland et al., 2013). The resulting effect size is Cohen's $d$.

Overall, $14 \%$ of predictive linear and quadratic models yielded statistically significant results between the key question predictors and gains in child outcomes. There was a statistically significant and positive linear association between instructional support and gains in children's early writing (Dictation: $p<.05, d=.09$ ), and gains in one measure of child executive function (cognitive inhibitory control, as measured by the PT task: $p<.05, d=.06$ ) at

Table 3

Descriptive Statistics for Child Outcomes at the Beginning and at the End of Prekindergarten

\begin{tabular}{|c|c|c|c|c|c|c|c|c|c|c|c|}
\hline \multirow[b]{2}{*}{ Outcome } & \multirow[b]{2}{*}{ Assessment } & \multicolumn{5}{|c|}{ Beginning of prekindergarten } & \multicolumn{5}{|c|}{ End of prekindergarten } \\
\hline & & $N$ & $M$ & $S D$ & Min & Max & $N$ & $M$ & $S D$ & Min & Max \\
\hline Language & WM Vocabulary & 1,711 & 18.37 & 4.64 & 0 & 36 & 1,710 & 21.95 & 4.97 & 0 & 37 \\
\hline Early literacy & WM Letter-Word & 1,687 & 5.55 & 2.40 & 0 & 17 & 1,648 & 8.13 & 3.38 & 0 & 37 \\
\hline Early writing & WM Dictation & 1,747 & 5.94 & 1.99 & 0 & 15 & 1,658 & 8.29 & 1.78 & 0 & 16 \\
\hline Early numeracy & WM Applied Problems & 1,441 & 7.87 & 3.44 & 0 & 23 & 1,594 & 11.29 & 3.54 & 0 & 24 \\
\hline Executive function & PT & 1,769 & 7.59 & 4.75 & 0 & 16 & 1,699 & 10.49 & 4.92 & 0 & 16 \\
\hline Executive function & DCCS & 1,836 & 3.58 & 2.57 & 0 & 6 & 1,723 & 4.27 & 2.24 & 0 & 6 \\
\hline
\end{tabular}

Note. $N=1,868$. Percentage of missing data was between $8 \%$ and $15 \%$. WM $=$ Woodcock-Muñoz; PT $=$ Pencil Tapping; DCCS $=$ Dimensional Change Card Sort. 


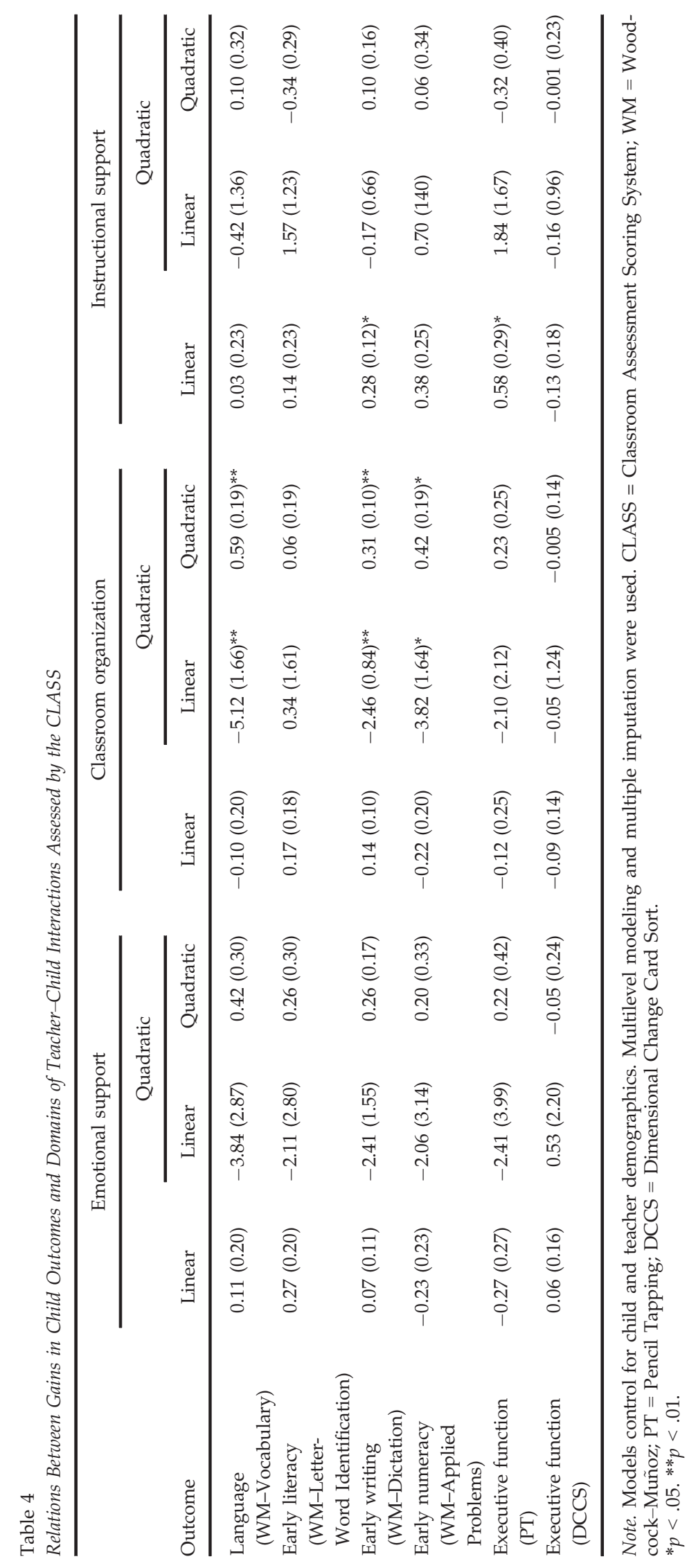


the end of prekindergarten. The effect sizes of these associations were small. No other associations between instructional support and child outcomes were found. Furthermore, no significant linear associations were found among child outcomes and classroom organization or emotional support.

There also were significant and positive quadratic associations between classroom organization and gains in language, early writing, and early numeracy skills at the end of prekindergarten. This indicates that the relation between classroom organization and child outcomes (language, early writing, and early numeracy) appears to be stronger at higher levels of classroom organization. Notably, the shape and strength of the quadratic relations found in this study are similar to those reported by prior research (Burchinal, Kainz, et al., 2011; Weiland et al., 2013). In the online Supporting Information, we include a figure illustrating the fitted quadratic association between classroom organization assessed by the CLASS and child outcomes (see Figure S1). No statistically significant quadratic relations were found between emotional or instructional support and child outcomes, and no statistically significant associations were found between children's executive function and the three domains of teacher-child interactions assessed by the CLASS.

Threshold/Spline Regression Analyses Between Domains of Teacher-Child Interactions and Child Outcomes in Chile

Table 5 shows the results from applying spline regression techniques using conceptually determined cut points derived from the CLASS manual (Pianta et al., 2008), and used elsewhere in this literature (see Burchinal et al., 2010; Burchinal, Xue, et al., 2011) as follows: 5 for emotional support and classroom organization. For instructional support, we used a slightly lower cut point (2.00) than elsewhere in the literature (2.75) because of the distribution of our data. Only 15\% of classrooms had instructional support scores $>2.75$. The percentage of classrooms falling below our selected cut point values were as follows: emotional support, $72 \%$ $(N=46)$; instructional support, $72 \%(N=46)$; and classroom organization, $81 \%(N=52)$.

Using this technique, $28 \%$ of the predictive models yielded statistically significant results between CLASS classroom quality constructs and gains in children's outcomes. Within its higher range, classroom organization showed a positive and statistically significant association with children's language skills $(p<.01, d=.07)$, early writing (Dictation: $p<.01, d=.10$ ), and early numeracy (Applied Problems: $p<.05, d=.07$ ). Higher range emotional support was positively and statistically significantly associated with children's early writing (Dictation: $p<.05, d=.10$ ). Within its lower range, emotional support was negatively related to lower levels of executive function (PT task: $p<.05, d=-.03$ ). Levels of instructional support were not related to child outcomes in this analysis. No other significant association was found between levels of classroom quality and gains in child outcomes. Effect sizes (Cohen's $d$ ) were all small, for lower and higher quality levels.

\section{Discussion}

This is one of the first studies conducted outside the United States to offer evidence supporting the existence of three domains of teacher-child interactions that are central to children's learning in the

Results of Spline Regression Analyses Predicting Child Outcomes From Domains of Teacher-Child Interactions Assessed by the CLASS in the Chilean Sample

\begin{tabular}{|c|c|c|c|c|c|c|}
\hline & \multicolumn{2}{|c|}{ Emotional support } & \multicolumn{2}{|c|}{ Classroom organization } & \multicolumn{2}{|c|}{ Instructional support } \\
\hline & Lower & Higher & Lower & Higher & Lower & Higher \\
\hline Language (WM-Vocabulary) & $-0.20(0.31)$ & $1.08(0.83)$ & $-0.40(0.21)$ & $2.79(0.87)^{* *}$ & $-0.24(0.48)$ & $0.41(0.79)$ \\
\hline Early literacy (WM-Letter-Word Identification) & $0.20(0.30)$ & $0.36(0.82)$ & $0.19(0.20)$ & $0.12(0.83)$ & $0.60(0.44)$ & $-0.87(0.73)$ \\
\hline Early writing (WM-Dictation) & $-0.18(0.15)$ & $0.85(0.43)^{*}$ & $-0.01(0.11)$ & $1.38(0.45)^{* *}$ & $0.11(0.24)$ & $0.25(0.39)$ \\
\hline Early numeracy (WM-Applied Problems) & $-0.34(0.33)$ & $0.41(0.92)$ & $-0.41(0.22)$ & $1.85(0.92)^{*}$ & $0.56(0.49)$ & $-0.35(0.84)$ \\
\hline Executive function (PT) & $-0.78(0.40)^{*}$ & $1.60(1.04)$ & $-0.14(0.28)$ & $0.03(1.19)$ & $0.88(0.60)$ & $-0.64(1.01)$ \\
\hline Executive function (DCCS) & $-0.04(0.23)$ & $0.33(0.62)$ & $-0.08(0.16)$ & $0.16(0.65)$ & $0.01(0.35)$ & $-0.26(0.59)$ \\
\hline
\end{tabular}

Note. Models control for child and teacher demographics. Multilevel modeling and multiple imputation were used. CLASS = Classroom Assessment Scoring System; WM = Woodcock-Muñoz; PT = Pencil Tapping; DCCS = Dimensional Change Card Sort. ${ }^{*} p<.05 .{ }^{* *} p<.01$. 
classrooms. These domains have been previously conceptualized through the teaching through interactions framework (Hamre \& Pianta, 2007) and assessed by the CLASS (Pianta et al., 2008). Our data supported the existence of three distinctive yet interrelated domains of teacher-child interactions in Chile: emotional support, classroom organization, and instructional support. We also found correlational evidence that children made stronger gains in language, academic (early writing and numeracy), and executive function (i.e., cognitive inhibitory control but not attention shifting) skills when classroom emotional support, classroom organization, and instructional support were higher.

Notably, our findings are consistent with prior research conducted in U.S. prekindergarten and kindergarten classrooms supporting the teaching through interactions framework (e.g., the National Center for Early Development and Learning [NCEDL] Multi-State Pre-K; Pianta et al., 2005; and the NCEDL State-Wide Early Education Pre-K Program). In particular, the magnitudes of the indexes of fit of the models tested with Chile data in our study were similar to those in these previous U.S. studies and to those reported in the Hamre et al. (2013) and Pakarinen et al. (2010) studies. Overall, this study supports the generalizability of the inferences regarding the value of teacher-child interactions in children's learning and development, based on a conceptual framework and an observational measure developed in North America, to urban Chile.

In line with prior research conducted in Chile (Strasser et al., 2009), and Araujo et al.'s (2014) study using the CLASS in Ecuador, we found that instructional support in prekindergarten classrooms in Chile was low $(M=1.75$ in Chile, $M=1.15$ in Ecuador). In the United States, instructional support tends to be in the low-middle range $(M s=1.84$ to $2.68)$, while in Finland it is in the middle range $(M=3.97)$. Two plausible reasons for such low levels of instructional support in Chile are the lack of coaching in teacher professional development programs and research-based curricula to support classroom instruction (Yoshikawa et al., in press). Although the Chilean government recently developed national curricular bases of early childhood education and care (Peralta, 2011), they serve more as benchmarks than content-based guidelines to support pedagogical practices in the classroom. We also found that emotional support and classroom organization in Chilean classrooms were in the middle range ( $M s=4.65$ and 4.29 , respectively). In the United States and Finland, these domains of teacher-child interactions tend to be in the middlehigh range (United States: $M s=4.36$ to 5.70 in emotional support and 4.66 to 4.97 in classroom organization; Finland: $M s=5.3$ and 5.34, respectively).

Another main contribution of this study is the evidence of positive and statistically significant associations, albeit small, between the domains of teacher-child interactions conceptualized by the teaching through interactions framework and children's outcomes. Specifically, in linear models, higher instructional support was linked to larger gains in prekindergarten children's academic skills (early writing) and executive function (cognitive inhibitory control). In both quadratic and spline models, higher levels of classroom organization were linked to larger gains in children's language and academic skills (early writing and numeracy). In addition, in spline models, classroom emotional support predicted gained in children's academic skills (early writing), but only in the higher range of emotional support. Notably, all three domains of teacher-child interactions (emotional support, classroom organization, instructional support) in our Chilean sample were related to at least one measure of children's academic skill. Our findings are in line with prior studies documenting within-domain contributions, that is, instructional support influences academic and language skills, and cross-domain contributions of teacher-child interactions to children's developmental outcomes, that is, emotional support influences academic and executive function skills, instructional support influences executive function skills, and classroom organization influences academic and language skills (for a review of within- and cross-domain contributions, see Downer et al., 2010). Taken together, our findings suggest that the pathways through which quality of teacher-child interactions may influence children's development and learning are complex, and they further support the idea that children's socioemotional, self-regulation, cognitive, and academic learning are intertwined, particularly in the early years.

Across models, the magnitude of the effect sizes of the associations between domains of teacherchild interactions and gains in children's outcomes in Chile was small. This is not surprising considering the consistently small size of the association between the CLASS factors and child outcomes in other studies conducted in the United States, with most effect sizes under 0.20 . These small effect sizes are found, regardless of type of early education center or model specifications, including linear, nonlinear, and threshold or spline regression models and 
across multiple regression, change score, and residualized change approaches (Burchinal et al., 2010; Burchinal, Kainz, et al., 2011; Zaslow et al., 2011). Replicating the finding of limited predictive power outside the United States might suggest that the true effects of classroom quality on prekindergarteners' development are in fact small.

Other researchers have interpreted the small effect sizes of classroom quality as indicating: (a) some inherent constraints on the power of the CLASS to detect the domains of teacher-child interactions that improve children's academic, language, and executive function skills (Burchinal et al., 2010; Zaslow et al., 2011); (b) the need to make more repeated observations of classrooms given the variability within teachers' practices, and the need to look for other characteristics of children's classrooms experiences that contribute to their learning (Zaslow et al., 2011); and (c) measurement error: A study in Ecuador that randomly assigned 15,000 kindergarteners to classrooms found that the CLASS was a stronger predictor of children's outcomes when the teacher's CLASS score from the previous year was used to instrument their current year score (e.g., effect size for language and a CLASS total score was 0.06 in an OLS specification vs. 0.15 in an IV specification; Araujo et al., 2014).

There are two important caveats that lead to the need for caution in the interpretation of our results and the implications for studies conducted outside the United States using the teaching through interactions framework and its corresponding observational tool, the CLASS. First, correlations among residuals in emotional support and classroom organization in our models indicate shared variance that is not explained by either of these constructsdespite the fact that the two-factor model (i.e., grouping emotional support and classroom organization into a single domain) does not have a better fit than the three-factor model. The common component that is revealed by the correlation among residuals might indicate issues related to the CLASS - the observational instrument itself (i.e., shared method variance) or possibly, the existence of a new, fourth domain of teacher-child interactions that contributes to children's learning and development. Although this is the first published study to report these correlations among residuals, other studies in the United States, Finland, and Ecuador have reported remarkably strong relations between and among the domains of teacher-child interactions (Araujo et al., 2014; Hamre et al., 2013; Pakarinen et al., 2010). To a certain extent, this is not surprising because many of the teachers' behav- iors examined by this framework and assessed by the CLASS are likely to depend on each other and to covary. For example, a teacher who is supportive of children's autonomy and encourages their talk (i.e., high regard for student perspectives, within emotional support) is more likely to maximize students' engagement, interests, and their abilities to learn from classroom activities (i.e., high instructional learning formats, within classroom organization).

To further understand the relations between and among domains of teacher-child interactions, Hamre, Hatfield, Pianta, and Jamil (2014) used bifactor analysis rather than CFA to analyze data collected on 325 preschool classrooms in the United States. There are some trade-offs of using bifactor analysis versus CFA (Reise, 2012). On the one hand, bifactor analyses are particularly suitable for representing measures of broad constructs that include multiple and distinct domains, allowing researchers to interpret the results more easily. On the other hand, assuming orthogonality (i.e., perfectly independent factor structure) as bifactor models require might not necessarily capture the true nature of the phenomenon at stake and limits the applications of this technique. Given these trade-offs, we decided that as a first step toward examining the validity of the CLASS in other cultural contexts we should use a CFA rather than a bifactor analysis. Because CLASS data have been recently collected from Ecuador (Araujo et al., 2014) and Colombia (MaldonadoCarreño \& Votruba-Drzal, 2014), in future work we will examine whether using bifactor analyses with CLASS data in more than one Latin American country yields similar results to those found with U.S. data. In particular, it would be interesting to test whether associations with child outcomes hold when domains of teacher-child interactions are entered simultaneously into prediction modelsone of the main advantages of bifactor analyses.

The second caveat is related to negative climate, one of the dimensions pertaining to the domain of emotional support. In our model, negative climate had a lower contribution (loading of .23) to the emotional support domain than other dimensions making up that domain (loadings above .61). This result is in line with data from Finland showing that negative climate had poor discriminant validity. This was because most classrooms received the same (lowest) score indicating that negativity is seldom present. The authors thus excluded it from their final model of classroom quality (Pakarinen et al., 2010). In the case of Chile, on the other hand, negative climate scores did show variation. However, the negative climate item contributed only 
weakly to the emotional climate factor. For comparability, we retained this dimension in our crosscountry comparisons.

Negative climate is an excellent illustration of how culture shapes adult-child interactions and why studies of cross-cultural validity of tools like the CLASS are essential. Culture determines the patterns of teacher-child interactions that are central to children's development and learning. According to the teaching through interactions conceptual framework, negative climate reflects the presence of negativity in the classroom, including sarcasm, disrespect, and severe negativity (i.e., bullying, victimization), punitive control (i.e., yelling, threats, physical control), and negative affect (i.e., anger, peer aggression, irritability), and is negatively associated with child development (Pianta et al., 2008). However, in the Chilean context, as in many other Latin American countries, behaviors such as teasing, sarcasm, and shaming are sometimes seen by adults as acceptable social mechanisms to control children's behavior (Miller, 1986). Teasing may serve to secure obedience from the child, direct the child's attention, and simultaneously engage in fun and amusement. In certain communities, teasing is not interpreted as an attack or threat because both adults and children recognize it as a "familiar script" and appreciate the function it serves (Miller, 1986). From this perspective, it is evident why low negative climate in Chilean classrooms might not be related to high emotional support. In studies using the CLASS in Colombia (Maldonado-Carreño \& Votruba-Drzal, 2014) and Ecuador (Araujo et al., 2014), negative climate showed a weaker correlation with emotional support than the other component subscales. These results raise the issue of whether negative climate is a relevant dimension of teacher-child interactions in countries other than the United States. Further research is needed in order to understand the construct of negative climate and its relation to teacher-child interactions in countries other than the United States.

One limitation of the present study is the method used to collect Chilean classroom data. Typically, studies in the United States have followed a live coding procedure where assessors observe classrooms in cycles of $20 \mathrm{~min}$ and then score each dimension of teacher-child interaction using a 7-point scale (see Pianta et al., 2008). In our study, we videotaped classrooms for the entire duration of the school day and selected four 20-min video segments based on the same criteria used in the CLASS manual. Although other published studies have used this same videotape procedure in the United States (Allen et al., 2013) and in Latin America (Araujo et al., 2014), we acknowledge that this methodological variation requires further investigation. Hence, replication using live coding of Chilean classrooms is important to further validate our findings. We also acknowledge that: (a) our sample is not representative of all prekindergarten programs in Chile; we have yet to determine whether our findings are specific to urban areas and public prekindergarten programs in Chile; and (b) we did not include assessments of socioemotional competence; typically, emotional support is positively associated with children's social and emotional skills. Thus, we might be getting a limited view of the predictive validity of this particular domain of teacher-child interactions in this study.

In light of the many particularities of the organization of early childhood education settings in Chile, it is remarkable that we found evidence for both construct and predictive validity of the teaching through interactions conceptual framework as assessed by the CLASS. Such evidence has policy implications, as the ability of researchers and policy makers to make informed evaluations of early childhood programs and investments is contingent upon having a common scale derived from cross-study assessments. In the United States, cross-study data have been critical in revealing that the quality of instructional support in preschool programs is quite low (Yoshikawa et al., 2013). Validating the CLASS in other settings can help us to understand how the quality of teacherchild interactions varies across settings and countries, and can help in targeting early childhood education reforms and resources accordingly.

In the past decades, Chile has dramatically increased its investment in early childhood education; many of the services that were originally reserved for the most privileged portion of the population are now accessible to most Chilean families (Contreras, Herrera, \& Leyton, 2007). As a result, prekindergarten and kindergarten and programs in Chile are starting to be seen as opportunities for cognitive and literacy development, rather than simply as places for socialization and play. Valid assessments of classroom quality are an essential part of maximizing the returns of Chile's early childhood investments.

\section{References}

Allen, P., Gregory, A., Mikami, A., Lun, J., Hamre, B., \& Pianta, R. (2013). Observations of effective teacher-student interactions in secondary school classrooms: Pre- 
dicting student achievement with the Classroom Assessment Scoring System-Secondary. School Psychology Review, 42, 76-98.

Araujo, C., Carneiro, P., Cruz-Aguayo, Y., \& Schady, N. (2014). A helping hand? Teacher quality and learning outcomes in kindergarten. Unpublished manuscript.

Bierman, K. L., Domitrovich, C. E., Nix, R. L., Gest, S. D., Welsh, J. A., Greenberg, M. T., . . . Gill, S. (2008). Promoting academic and social-emotional school readiness: The head start REDI program. Child Development, 79, 1802-1817. doi:10.1111/j.1467-8624.2008.01227.x

Bornstein, M. H., Tamis-LeMonda, C. S., Hahn, C. S., \& Haynes, O. M. (2008). Maternal responsiveness to young children at three ages: Longitudinal analysis of a multidimensional, modular, and specific parenting construct. Developmental Psychology, 44, 867-874. doi:10. 1037/0012-1649.44.3.867

Bronfenbrenner, U., \& Morris, P. A. (1998). The ecology of developmental processes. In W. Damon \& R. M. Lerner (Eds.), Handbook of child psychology: Vol. 1. Theoretical models of human development (5th ed., pp. 9931029). New York, NY: Wiley.

Burchinal, M., Howes, C., Pianta, R. C., Bryant, D., Earl, D., Clifford, R., \& Barbarin, O. (2008). Predicting child outcomes at the end of kindergarten from the quality of pre-kindergarten teacher-child interactions and instruction. Applied Developmental Science, 12, 140-153. doi:10.1080/10888690802199418

Burchinal, M., Kainz, K., \& Cai, Y. (2011). How well do our measures of quality predict child outcomes? A meta-analysis and coordinated analysis of data from large-scale studies of early childhood settings. In M. Zaslow, I. Martinez-Beck, K. Tout, \& T. Halle (Eds.), Quality measurement in early childhood settings (pp. 1131). Baltimore, MD: Brookes.

Burchinal, M., Vandergrift, N., Pianta, R., \& Mashburn, A. (2010). Threshold analysis of association between child care quality and child outcomes for low-income children in pre-kindergarten programs. Early Childhood Research Quarterly, 25, 166-176. doi:10.1016/j.ecresq. 2009.10.004

Burchinal, M., Xue, Y., Tien, H., Auger, A., \& Mashburn, A. (2011, April). Testing for thresholds in associations between child care quality and child outcomes. Paper presented at the biennial meeting of the Society for Research in Child Development, Montreal, Canada.

Contreras, D., Herrera, R., \& Leyton, G. (2007). Impacto de la educación preescolar sobre el logro educacional: Evidencia para Chile [Impact of preschool education on educational achievement: Evidence in Chile]. Unpublished manuscript, Universidad de Chile, Santiago de Chile.

Diamond, A., \& Taylor, C. (1996). Development of an aspect of executive control: Development of the abilities to remember what I said and to "Do as I say, not as I do." Developmental Psychobiology, 29, 315-334. doi:10. 1002/(SICI)1098-2302(199605)29:4<315::AID-DEV2>3.0. $\mathrm{CO} ; 2-\mathrm{T}$
Downer, J. T., Sabol, T., \& Hamre, B. K. (2010). Teacherchild interactions in the classroom: Toward a theory of within- and cross-domain links to children's developmental outcomes. Early Education and Development, 21, 699-723. doi:10(1080/10409289), 2010, 497453

Graham, J. W. (2009). Missing data analysis: Making it work in the real world. Annual Review of Psychology, 60, 549-576. doi:10.1146/annurev.psych.58.110405.085530

Halgunseth, L. C., Ispa, J. M., \& Rudy, D. (2006). Control in Latino families: An integrated review of the literature. Child Development, 77, 1282-1297. doi:10.1111/j. 1467-8624.2006.00934.x

Hamre, B. K., Hatfield, B., Pianta, R., \& Jamil, F. (2014). Evidence for general and domain-specific elements of teacher-child interactions: Associations with preschool children's development. Child Development, 85, 12571274. doi:10.1111/cdev.12184

Hamre, B. K., \& Pianta, R. C. (2005). Can instructional and emotional support in the first grade classroom make a difference for children at risk of failure? Child Development, 76, 949-967. doi:10.1111/j.1467-8624.2005. 00889.x

Hamre, B. K., \& Pianta, R. C. (2007). Learning opportunities in preschool and early elementary classrooms. In R. Pianta, M. Cox, \& K. Snow (Eds.), School readiness $\mathcal{E}$ the transition to kindergarten in the era of accountability (pp. 49-84). Baltimore, MD: Brookes.

Hamre, B. K., Pianta, R. C., Downer, J. T., DeCoster, J., Mashburn, A. J., Jones, S., . . Hamagami, A. (2013). Teaching through interactions-Testing a developmental framework for understanding teacher effectiveness in over 4,000 U.S. early childhood and elementary classrooms. The Elementary School Journal, 113, 461-487. doi:10.1086/669616

Harwood, R., Leyendecker, B., Carlson, V., Asencio, M., \& Miller, A. (2002). Parenting among Latino Families in the U.S. In M. Bornstein (Ed.), Handbook of parenting (Vol. 4, pp. 21-46). Mahwah, NJ: Erlbaum.

Howes, C., Burchinal, M., Pianta, R., Bryant, D., Early, D., Clifford, R., \& Barbarin, O. (2008). Ready to learn? Children's pre-academic achievement in pre-kindergarten programs. Early Childhood Research Quarterly, 23, 27-50. doi:10.1016/j.ecresq.2007.05.002

Landry, S. H., Anthony, J. L., Swank, P. R., \& MonsequeBailey, P. (2009). Effectiveness of comprehensive professional development for teachers of at-risk preschoolers. Journal of Educational Psychology, 101, 448-465. doi:10. $1037 / \mathrm{a} 0013842$

Maldonado-Carreño, C., \& Votruba-Drzal, E. (2014). Early childhood development and preschool quality in Bogota, Colombia. Unpublished manuscript, Universidad de los Andes, Bogota, Colombia.

Mashburn, A. J., Pianta, R. C., Hamre, B. K., Downer, J. T., Barbarin, O., Bryant, D., . . . Howes, C. (2008). Measures of classroom quality in prekindergarten and children's development of academic, language, and social skills. Child Development, 79, 732-749. doi:10.1111/j. 1467-8624.2008.01154.x 
Miller, P. J. (1986). Teasing as language socialization and verbal play in a white, working-class community. In B. B. Schieffelin \& E. Ochs (Eds.), Language socialization across cultures (pp. 199-212). Cambridge, UK: Cambridge University Press.

Ministerio de Educación. (2013). Informe Final: Estado de la educación parvularia en Chile [Final report: Status of early childhood education in Chile]. Unpublished manuscript, Santiago, Chile.

Muñoz-Sandoval, A. F., Woodcock, R. W., McGrew, K. S., \& Mather, N. (2005). Batería III Woodcock-Muñoz. Itasca, IL: Riverside.

Murnane, R. J., \& Willett, J. B. (2010). Methods matter: Improving causal inference in educational and social science research. New York, NY: Oxford University Press.

National Institute of Child Health and Human Development Early Child Care Research Network. (1996). Characteristics of infant child care: Factors contributing to positive caregiving. Early Childhood Research Quarterly, 11, 269-306.

National Institute of Child Health and Human Development Early Child Care Research Network. (2005). Early child care and children's development on the primary grades: Results from the NICHD Study of Early Child Care. American Educational Research Journal, 42, 537-570. doi:10.3102/00028312042003537

Pakarinen, E., Kiura, N., Lerkkanen, M. K., Pokkeusb, A. M., Ahonena, T., \& Nurmi, J. (2011). Instructional support predicts children's task avoidance in kindergarten. Early Childhood Research Quarterly, 26, 376-386. doi:10. 1016/j.ecresq.2010.11.003

Pakarinen, E., Lerkkanen, M., Pokkeus, A., Kiuru, N., Siekkinen, M., Rasku-Puttonen, H., \& Nurmi, J. (2010). A validation of the classroom assessment scoring system in Finnish kindergartens. Early Education and Development, 21, 95-124. doi:10.1080/10409280902858764

Peralta, M. V. (2011). Early childhood education and public care policies in Chile: A historical perspective to analyze the present. International Journal of Child Care and Education Policy, 5, 17-27.

Pianta, R. C., \& Hamre, B. K. (2009). Classroom processes and positive youth development: Conceptualizing, measuring, and improving the capacity of interactions between teachers and students. New Directions for Youth Development, 121, 33-46. doi:10.1002/yd.295

Pianta, R. C., Howes, C., Burchinal, M., Bryant, D., Clifford, R., Early, C., \& Barbarin, O. (2005). Features of pre-kindergarten programs, classrooms, and teachers: Do they predict observed classroom quality and childteacher interactions? Applied Developmental Science, 9, 144-159. doi:10.1207/s1532480xads0903_2

Pianta, R. C., La Paro, K. M., \& Hamre, B. K. (2008). Classroom Assessment Scoring System (CLASS). Baltimore, MD: Brookes.

Pianta, R. C., La Paro, K. M., Payne, C., Cox, M. J., \& Bradley, R. (2002). The relation of kindergarten classroom environment to teacher, family, and school characteristics and child outcomes. The Elementary School
Journal, 102, 225-238. Retrieved from http:/ /www.jstor. org/stable/1002217

Ponitz, C. C., Rimm-Kaufman, S. E., Brock, L. L., \& Nathason, L. (2009). Early adjustment, gender differences, and classroom organizational climate in first grade. The Elementary School Journal, 110, 142-162. doi:10.1086/605470

Raver, C. C. (2004). Placing emotional self-regulation in sociocultural and socioeconomic contexts. Child Development, 75, 346-353. doi:10.1111/j.1467-8624.2004.00676.x

Reise, S. P. (2012). The rediscovery of bifactor measurement models. Multivariate Behavioral Research, 47, 667696. doi:10.1080/00273171.2012.715555

Rimm-Kaufman, S. E., Curby, T. W., Grimm, K. J., Nathanson, L., \& Brock, L. L. (2009). The contribution of children's self-regulation and classroom quality to children's adaptive behaviors in the kindergarten classroom. Developmental Psychology, 45, 958-972. doi:10. 1037 /a0015861

Rogoff, B. (2003). The cultural nature of development. New York, NY: Oxford University Press.

Schrank, F. A., McGrew, K. S., Ruef, M. L., Alvarado, C. G., Muñoz-Sandoval, A. F., \& Woodcock, R. W. (2005). Overview and technical supplement (Bateria III Woodcock-Muñoz Assessment Service Bulletin No. 1). Itasca, IL: Riverside.

Strasser, K., Lissi, M. R., \& Silva, M. (2009). Gestión del tiempo en 12 salas Chilenas de kindergarten: Recreo, colación y algo de instrucción [Time management in 12 Chilean kindergarten classrooms: Recess, breakfast and some instruction]. Psykhe, 18, 85-96. doi:10.4067/S071822282009000100008

U.S. Department of Health and Human Services, Administration for Children and Families. (2012). Advisory Committee on Head Start Research and Evaluation (Final Report). Retrieved from http://www.acf.hhs.gov/ sites/default/files/opre/eval_final.pdf

Vygotsky, L. (1978). Mind in society. The development of higher psychological processes. Cambridge, MA: Harvard University Press.

Weiland, C., Ulvestad, K., Sachs, J., \& Yoshikawa, H. (2013). Associations between classroom quality and children's vocabulary and executive function skills in an urban public prekindergarten program. Early Childhood Research Quarterly, 28, 199-209. doi:10.1016/j. ecresq.2012.12.002

Woodcock, R. W., Muñoz-Sandoval, A. F., Ruef, M., \& Alvarado, C. G. (2005). Woodcock-Muñoz Language Survey-Revised. Itasca, IL: Riverside.

Yoshikawa, H., Leyva, D., Snow, C. E., Treviño, E., Arbour, M. C., Barata, M. C., . . D'Sa, N. (in press). Experimental impacts of a teacher professional development program in Chile on preschool classroom quality and child outcomes. Developmental Psychology.

Yoshikawa, H., Weiland, C., Brooks-Gunn, J., Burchinal, M., Espinosa, L., Gormley, W., ... Zaslow, M. J. (2013). Investing in our future: The evidence base on preschool education. Washington, DC and New York, NY: Society for Research in Child Development and Foundation for Child Development. 
Zaslow, M., Martinez-Beck, I., Tout, K., \& Halle, T. (2011). Quality measurement in early childhood settings. Baltimore, MD: Brookes.

Zelazo, P. D. (2006). The Dimensional Change Card Sort (DCCS): A method of assessing executive function in children. National Protocols, 1, 297-301. doi:10.1038/ nprot.2006.46

\section{Supporting Information}

Additional supporting information may be found in the online version of this article at the publisher's website:
Figure S1. Plot of the Fitted Relation Between Classroom Organization (CLASS Score) and Children's Early Writing Skills (Woodcock-Muñoz Dictation Raw Score).

Table S1. Descriptive Statistics for Child Outcomes (Woodcock-Muñoz Standard Scores) at the Beginning and the End of Prekindergarten $(N=1,868)$ 